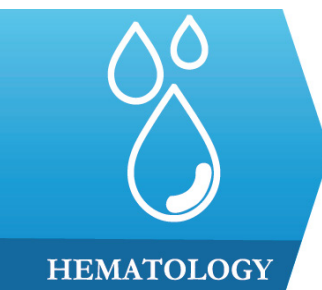

1) Department of Hematology, Iuliu Hatieganu University of Medicine and Pharmacy, Cluj-Napoca, Romania

2) Department of Pathology, Constantin Papilian Military Hospital, Cluj-Napoca, Romania

3) Department of Hematology, Ion Chiricuta Clinical Cancer Center, ClujNapoca, Romania

4) Medfuture Research Center for Advanced Medicine, Iuliu Hatieganu University of Medicine and Pharmacy, Cluj-Napoca, Romania

5) Department of Hematology, The Sixth Medical Center of PLA General Hospital, Beijing, China

6) South African Bioinformatics Institute, University of the Western Cape, Cape Town, South Africa

7) South African Medical Research Council, Cape Town, South Africa

8) Department of Hematology and Cell Biology, Faculty of Health Sciences, National Health Laboratory Services, University of the Free State, Bloemfontein, South Africa

9) Department of Pathology, The Sixth Medical Center of PLA General Hospital, Beijing, China

DOI: $10.15386 / \mathrm{mpr}-1777$

Manuscript received: 13.06 .2020

Received in revised form: 27.11.2020

Accepted: 29.03.2021

Address for correspondence:

ciprian.tomuleasa@iocn.ro

This work is licensed under a Creative Commons Attribution-NonCommercialNoDerivatives 4.0 International License

\title{
Correlation between the prevalence of T-cell lymphomas and alcohol consumption
}

\author{
Minodora Desmirean ${ }^{1,2}$, Cedric Richlitzki ${ }^{1}$, Sergiu Pasca ${ }^{1}$, \\ Patric Teodorescu ${ }^{1,3}$, Bobe Petrushev ${ }^{4}$, Sebastian Rauch ${ }^{1}$, \\ Jacob Steinheber ${ }^{1}$, Sabina Iluta ${ }^{3}$, Jiaxin Liu ${ }^{5}$, Delia Dima ${ }^{3}$, \\ Ravnit Grewal ${ }^{6,7,8}$, Weina Ma ${ }^{9}$, Liren Qian ${ }^{5}$, Ciprian Tomuleasa ${ }^{1,3,4}$
}

\begin{abstract}
Background and aims. Alcohol is a psychoactive substance that causes dependence, with many thousands of years in the history of mankind, being widely used in different cultures. According to the International Agency for Research on Cancer, alcohol is involved in the development of cancer, being directly associated with it. Considering that alcohol is involved in the initiation and dissemination of gastrointestinal malignancies, the objective of the study was to assess its role in the pathogenesis of T-cell lymphomas, as well as its possible correlation with chronic consumption.

Methods. The patient cohort was compiled from the Sixth Medical Center of the People's Liberation Army Navy General Hospital in Beijing, China. A total of 30 patients matched the criteria and were enrolled in the study. Statistical analysis of the raw data was performed using R Statistics version R 3.5.1. released on the 29.08.2018.

Results. Our data demonstrate that the most common extranodal involvment of T-cell lymphoma patients is represented in decreasing order by bone marrow, peritoneum, rhino-oropharynx and the liver-biliary system. Nodal involvement is mainly represented in decreasing order by the laterocervical, axillary, mediastinal and inguinal regions.
\end{abstract}

Conclusions. These findings may be of value in further research and practical/ clinical settings. Fever is the most common clinical feature and was present in most studied patients.

Keywords: T-cell lymphomas, alcohol consumption, pathophysiology

\section{Introduction}

Over the past century the incidence of non-Hodgkin lymphomas (NHL) has steadily risen, mainly the B-cell lymphomas, as they represent the majority of NHL [1-3]. T-cell and NK-cell lymphomas are generally underrepresented due to their low incidence overall. They also have a wide variability in different geographical regions and racial populations [4-6]. Tand NK-cell lymphomas are relatively rare and clinically either of these subtypes are aggressive and quite heterogenous [7]. The occurrence of adult T-cell lymphomas may be linked to previous viral infections with Human T-lymphotropic virus type 1 (HTLV-1) and Epstein-Barr virus (EBV) [8-14]. Considering that T-cell lymphomas in general, are a rarely occurring type of malignancy, its large number of subtypes represent only a few hundred cases annually.

While in North America the three most commen T-cell lymphomas are peripheral T-cell lymphoma - Not Otherwise Specified (PTCL-NOS), angioimmunoblastic T-cell lymphoma and anaplastic large-cell lymphoma ALKpositive (ALCL ALK-positive), Europe 
shows a relatively equal distribution with one exception: anaplastic large-cell lymphoma ALK-negative (ALCL ALK-negative) replaces ALCL ALK-positive of North America. In Asia, the prevalence of the three most common T-cell lymphomas is quite different, with a nearly equal distribution of PTCL-NOS, NK/T-cell lymphomas, and adult T-cell leukemia / lymphoma (ATLL). The latter two are up to twenty-five times more frequent in Asia than in North America or Europe [15-18].

Alcohol is a psychoactive substance with certain dependence producing properties and a long history of many thousands of years in human history and was widely used in different cultures [19]. Many factors have an impact on the total or individual consumption of alcoholic beverages, for example sociodemographic factors, economic development, religion, culture as well as individual factors such as gender, age, health status, personal economic wealth, and lifestyle [20-23]. To measure the level of alcohol consumption some indicators need to be defined and explained. The most important are the prevalence/number of current drinkers and abstainers in a region or country, as well as the total alcohol consumption in liters of pure alcohol per person per year and the alcohol consumption in grams of pure alcohol per person per day [24-27]. According to the WHO data from 2016 the total aclohol per capita consumption in the world population of age 15 years and older was on average 6.4 liters of pure alcohol annually which accounts for 13.9 grams of pure alcohol per day $[28,29]$. Elimination of alcohol mainly occurs in the liver by the alcohol dehydrogenase and cytochrome $\mathrm{P} 450$ oxidation of ethanol, a small percentage, below $1 \%$ is eliminated by breath, urine and sweat [30,31].

Alcohol dehydrogenase (ADH) is found in different organs throughout the body; it is found in the highest amounts in the liver, followed by GI tract, kidneys, nasal mucosa, testes, and in the uterus, it is located in the cytosolic fraction of the cell. It has a variety of oxidative functions and is involved in the steroid and bile acid metabolism. It oxidizes endogenous alcohol produced by microorganisms in the gut and exogenous ethanol and other alcohols consumed in the diet [32].

Racial groups express different amounts of the ADH1, which could explain a variation in the metabolism of alcohol. The International Agency for Research on Cancer (IARC) has classified acetaldehyde as a type 1 carcinogen in humans $[33,34]$.

Alcohol metabolism and the resulting metabolites lead to an increase in the risk of the development of certain cancers associated with the consumption of alcohol [35]. The World Health Organization (WHO) has identified chronic alcohol consumption as one of the top ten risk factors in terms of the years of life lost to premature mortality and years lived with disability. The most serious adverse health factors resulting from chronic alcohol consumption may be the development of cancer [36-38].
Taking into consideration that alcohol is involved in cancer initiation and dissemination, the objective of this research is devoted to T-cell lymphomas and its possible correlation with the chronic consumption of alcohol. Thus, we currently present the results of a pilot epidemiology study carried out as a result of a collaborative study between Romania and China.

\section{Methods \\ Patient cohort}

The patient cohort was compiled from the Sixth Medical Center of People's Liberation Army Navy General Hospital in Beijing, China, under the coordination of Dr. Liren Qian. The gathering of the data was conducted using patient charts from recent years with histologically confirmed and diagnosed T-cell lymphomas of all subtypes. Patients of any age, sex, geographical region, co-morbidities, risk factors and ethical background were included in this study. Inclusion in this study was not possible if data concerning the usage of alcohol in the past or present were not available. This led to the exclusion of the patient from the studied cohort. A total of 30 patients matched these criteria and were enrolled in the study. Data from the patient charts were translated in a preassembled Excel-Sheet with previously chosen important demographical and clinical characteristics with regard to the studied objective to give a precise overview of the patient and the accompanied pathology related features. A subdivision of the Excel-Sheet into three divisions for organizational purposes was conducted to assure a quick overview of the collected data.

\section{Statistical analysis}

Statistical analysis of the raw data was performed using $\mathrm{R}$ Statistics version $\mathrm{R}$ 3.5.1. released on the 29.08.2018.

\section{Results}

Patient demographics of the 30 enrolled patients is presented in table I (Demographical characteristics), table II (Extranodal sides) and table III (Nodal sides). The percentage of drinkers according to the histological subtypes of T-cell lymphomas is depicted in figure 1 . The $\mathrm{p}$-value $(\mathrm{p}=0.370)$ is not statistically significant, but this might be because of the small sample. "Drinkers" seem to present more frequently with angioimmunoblastic T-cell lymphoma (AITL), while "Never drinkers" seem to present more frequently with Adult T-cell Leukemia/Lymphoma (ATLL). If comparing AITL versus non-AITL the p-value is 0.0753 (a total of 38 patients would be needed to observe if there is statistical significance or not). If comparing ATLL versus non-ATLL the p-value is 0.632 . This brings the hypothesis that alcohol consumption might be a risk factor for developing AITL and should be tested on a larger cohort. 
Table I. Demographical characteristics.

\begin{tabular}{|c|c|c|}
\hline Demographic characteristics & Value & Value \\
\hline \multirow{2}{*}{ Sex } & Male & 26 \\
\hline & Female & 4 \\
\hline Mean age (sd) & & $49.93(20.55)$ \\
\hline \multirow{2}{*}{ Area } & Urban & 17 \\
\hline & Rural & 13 \\
\hline \multirow{3}{*}{ Fever } & No & 10 \\
\hline & Under 38 & 2 \\
\hline & Over 38 & 18 \\
\hline \multirow{3}{*}{ Weight loss } & No & 16 \\
\hline & Under $10 \%$ & 10 \\
\hline & Over $10 \%$ & 4 \\
\hline \multirow{2}{*}{ Night sweats } & No & 23 \\
\hline & Yes & 7 \\
\hline \multirow{5}{*}{ ECOG } & 0 & 0 \\
\hline & 1 & 21 \\
\hline & 2 & 8 \\
\hline & 3 & 1 \\
\hline & 4 & 0 \\
\hline \multirow{2}{*}{ Erythroderma } & No & 25 \\
\hline & Yes & 5 \\
\hline \multirow{2}{*}{ Raised rush } & No & 24 \\
\hline & Yes & 6 \\
\hline \multirow{2}{*}{ Pruritis } & No & 25 \\
\hline & Yes & 5 \\
\hline \multirow{2}{*}{ Fatigue } & No & 19 \\
\hline & Yes & 11 \\
\hline \multirow{2}{*}{ Headache } & No & 29 \\
\hline & Yes & 1 \\
\hline \multirow{2}{*}{ Neurologic symptoms } & No & 29 \\
\hline & Yes & 1 \\
\hline \multirow{2}{*}{ Cough } & No & 27 \\
\hline & Yes & 3 \\
\hline \multirow{2}{*}{ Dyspnea } & No & 28 \\
\hline & Yes & 2 \\
\hline \multirow{2}{*}{ Anorexia } & No & 18 \\
\hline & Yes & 12 \\
\hline \multirow{2}{*}{ Abdominal pain } & No & 25 \\
\hline & Yes & 5 \\
\hline
\end{tabular}

Table II. Extranodal sites.

\begin{tabular}{l|c} 
Extranodal sites & Value \\
\hline CNS & 1 \\
Eye and lacrimal glands & 0 \\
Rhino-Oro-Pharynx & 8 \\
Salivary gland & 0 \\
Thyroid & 1 \\
Parotid & 0 \\
Heart & 0 \\
Vascular system & 3 \\
Pericardium & 2 \\
Thymus & 1 \\
Lungs & 1 \\
Pleura & 0 \\
Liver and biliary system & 7 \\
Pancreas & 0 \\
Colon and rectum & 2 \\
Kidneys & 1 \\
Peritoneum & 10 \\
Genital system & 2 \\
Spleen & 5 \\
Bone & 3 \\
Skin & 2 \\
Subcutaneous & 2 \\
Muscle & 1 \\
Breast & 1 \\
Bone marrow & 11 \\
& CNS - Central Nervous Systen
\end{tabular}

CNS - Central Nervous System
Table III. Nodal sites.

\begin{tabular}{l|c} 
Nodal sites & Value \\
\hline Waldeyer's ring & 1 \\
Submandibular & 3 \\
Laterocervical & 21 \\
Axillary & 17 \\
Lung hilum & 6 \\
Mediastinum & 16 \\
Celiac & 2 \\
Lomboaortic & 3 \\
Mesenteric & 1 \\
Iliac & 7 \\
Inguinal & 14 \\
Crural & 1
\end{tabular}




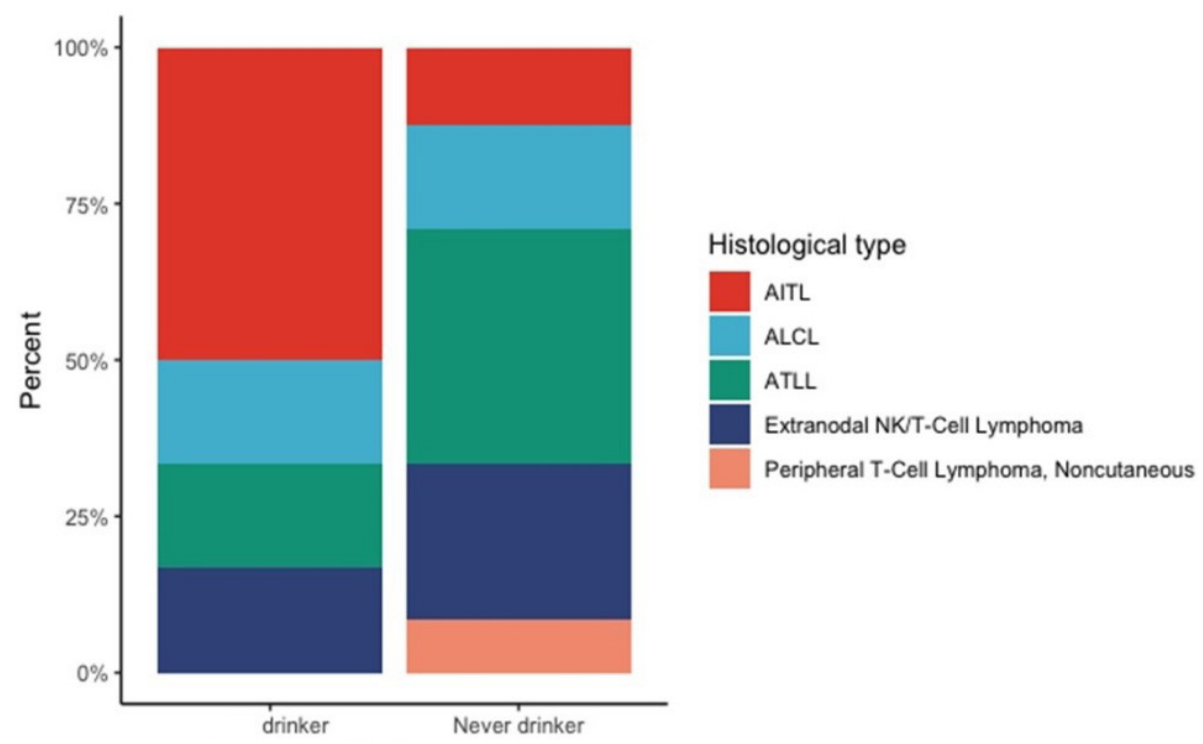

Figure 1. Percentage of drinkers according to the T-cell lymphoma subtypes. AITL- angioimmunoblastic T-cell lymphoma; ALCL anaplastic large cell lymphoma; ATLL - adult T-cell leukemia/lymphoma.

The drinking behavior according to the extranodal site involvement is depicted in figure 2, while the drinking behavior according to the nodal side involvement is depicted in figure 3 . Because of the small number of drinkers and former drinkers per extranodal site, it is not possible to draw a valid statistical conclusion and this graph is only descriptive. The most frequent four sites have similar distributions of drinkers. Other nodal sites do not have enough observations that would make them important.

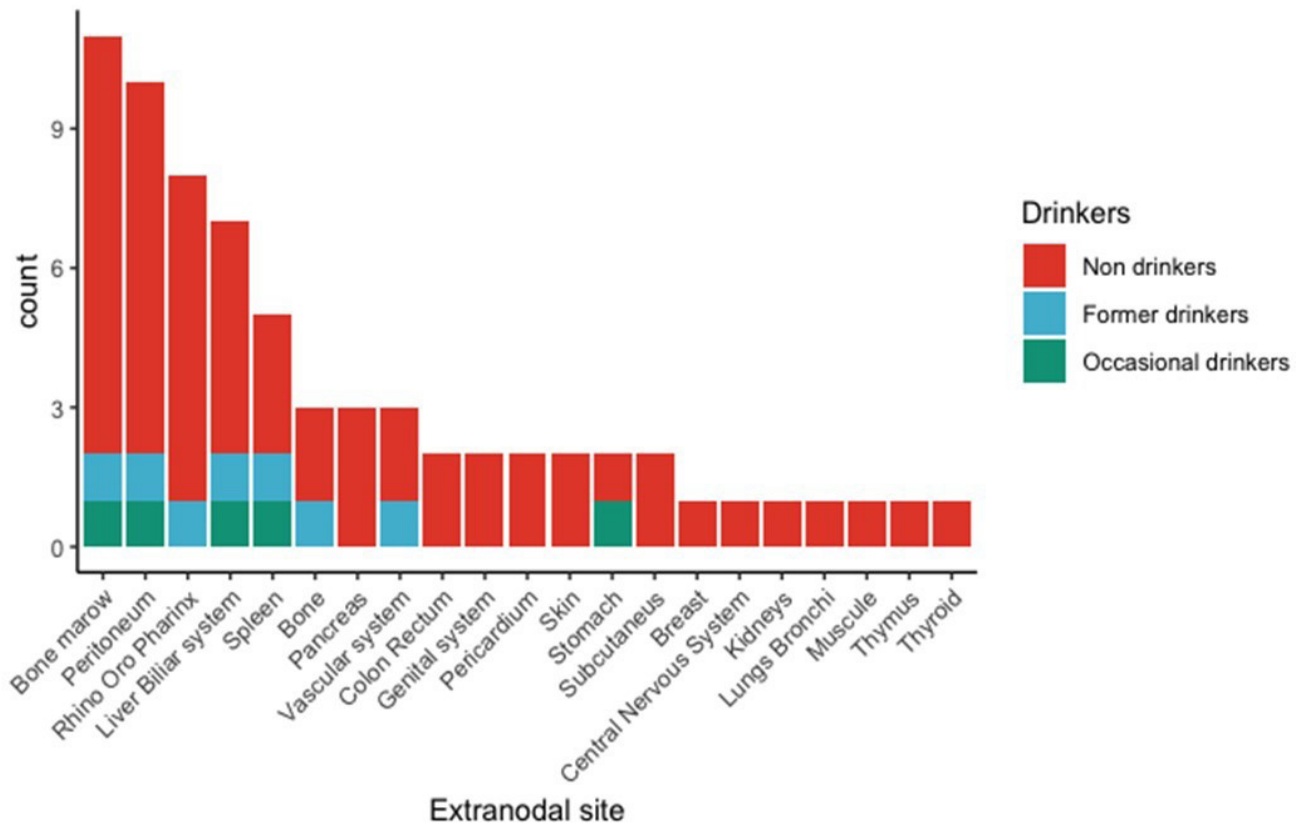

Figure 2. Drinking behavior according to the extranodal site involvement. 


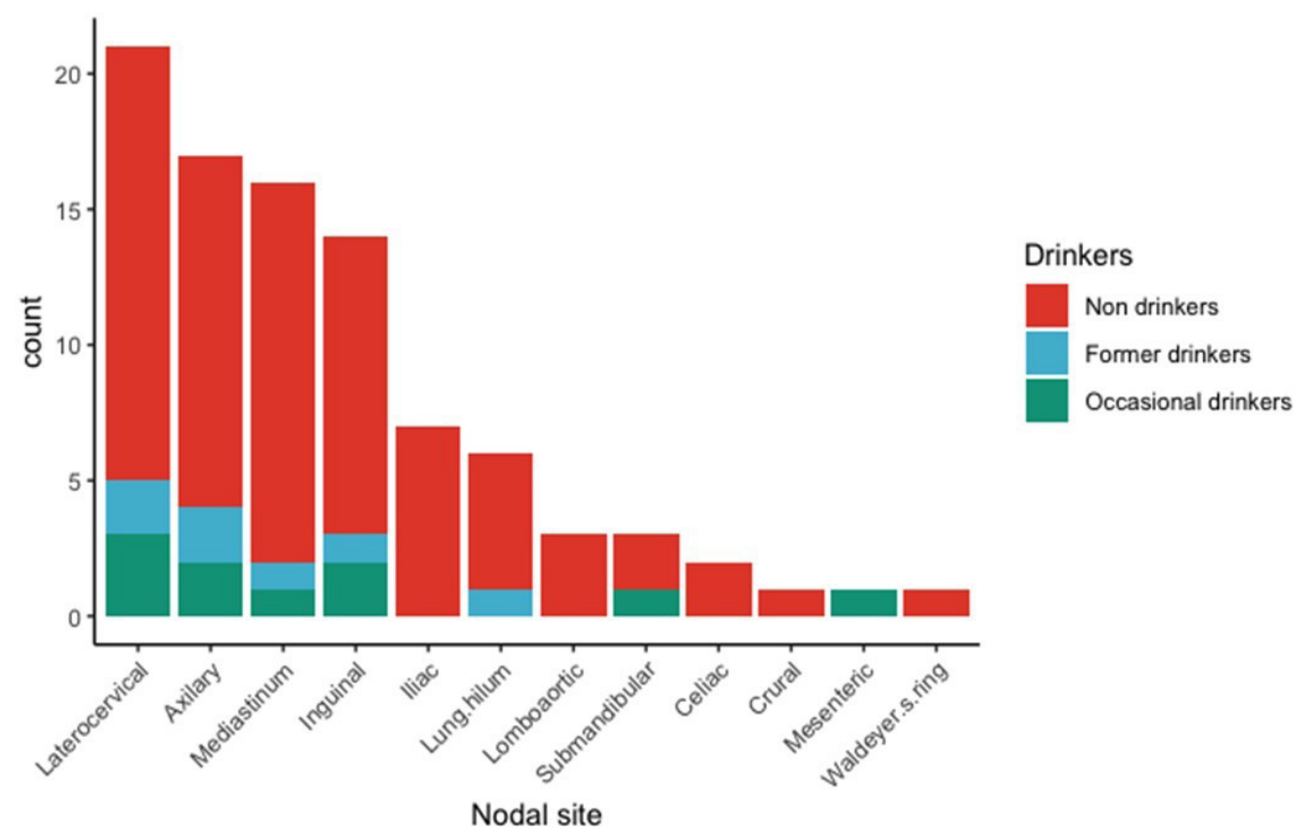

Figure 3. Drinking behavior according to the nodal site involvement.

The correlation between drinking behavior and clinical symptoms is shown in figure 4 . Fever was close to statistical significance $(p=0.0741)$, but all 6 alcohol consumers had fever and 20 out of 30 patients had fever. There might have been a result regarding fever if a larger cohort would have been considered. Statistical analysis includes $p=0.0605$ for rural urban, $p=0.00256$ for smoking and $p=0.0843$ for education. Smoking should also be considered when expanding the cohort, as it will act as a confounding variable. Education and rural/urban areas, although they did not reach the cutoff of 0.05 , should be observed as they might reach statistical significance in a larger cohort and act as confounders.

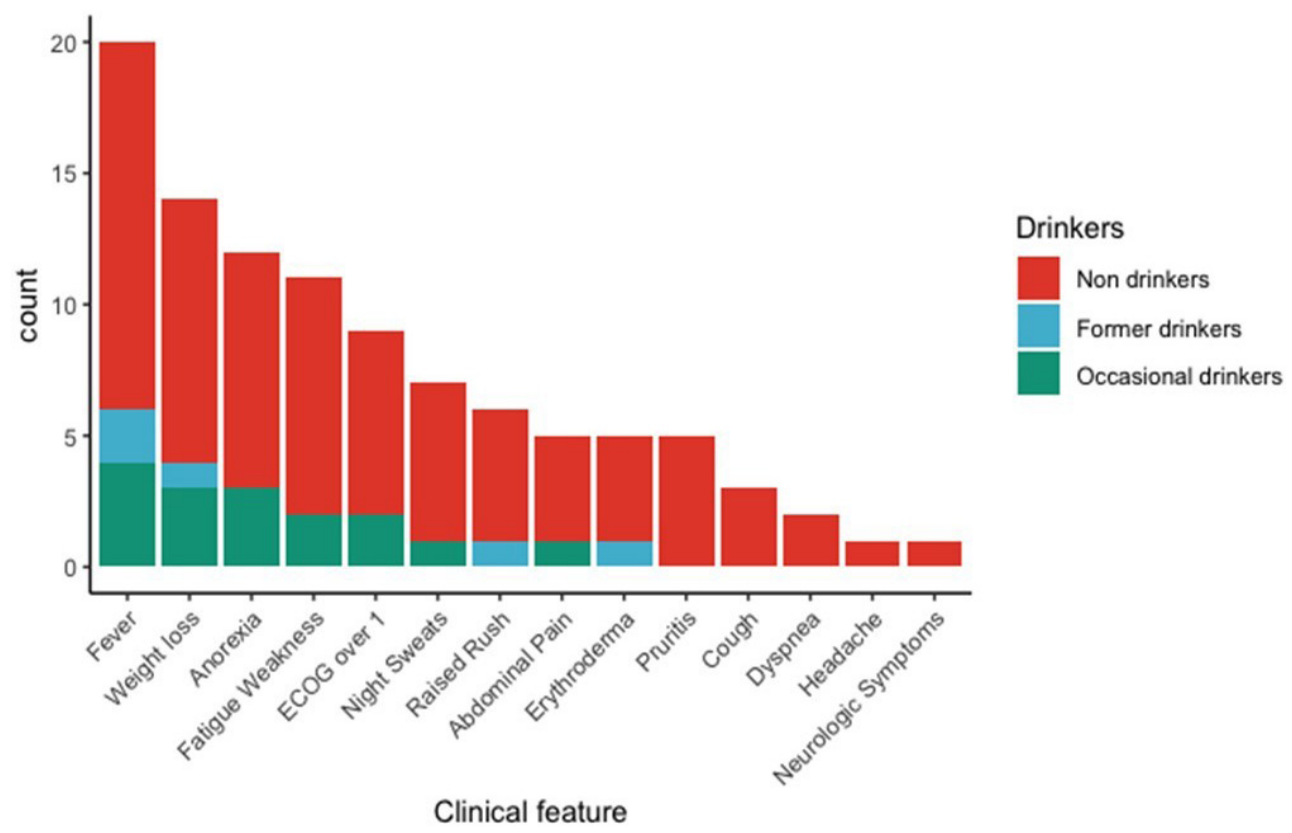

Figure 4. Correlation between drinking behavior and symptoms. 


\section{Discussion}

Commercially produced alcoholic beverages belong to the most consumed source of alcohol in developed countries worldwide. They include mainly beer produced from barley, wine produced from grapes and different types of distilled beverages [39]. Alcohol/Ethanol content can vary heavily between the different kinds of beverages. The WHO defines as current drinkers the percentage of those in the population aged 15 years and older who have consumed alcoholic beverages in the previous 12-month period. Total alcohol per capita consumption (APC) is defined as the total (recorded plus estimated unrecorded) alcohol per capita (i.e. persons aged 15 years and older) consumption within a calendar year in liters of pure alcohol, adjusted for tourist consumption. This indicator is used for the total population of 15 years and older (including non-drinkers) and for current drinkers only in the population [40].

The countries of the WHO European Region top the list of the highest per capita consumption of alcohol worldwide with 10 liters or more annually. In a few exceptions a relatively equal consumption is observed in countries from the WHO Africa Region e.g. Nigeria, from the WHO Region of the Americas e.g. Uruguay or in Australia and New Zealand. Also, a high consumption of 7.5-9.9 liters of pure alcohol per capita is found in the WHO Regions of Americas and the Western Pacific Region with a high income but also in some countries of the African Region. The lowest per capita consumption of less than 2.5 liters in found in the WHO Eastern Mediterranean Region and in Muslim-majority countries such as Niger in WHO African Region, Indonesia in the WHO South-East Asia Region (SEAR), or Azerbaijan in the WHO European Region [29].

According to the International Agency for Research on Cancer (IARC), alcohol as a carcinogen, is involved in the development and directly associated with cancer of the oral cavity, pharynx, larynx, esophagus, liver, colorectum, and the female breast. Approximately 389,000 of these cancers and thus $3.6 \%$ of its total occurrence are related directly with chronic alcohol consumption [41]. Since 2010 alcohol was classified as type 1 carcinogen by the International Agency for Research on Cancer (IARC), today both alcohol and the acetaldehyde metabolite are classified as type 1 carcinogens. The development of cancer was proven to follow a J-shaped risk profile where the risk increases dramatically with a higher amount of exposure to risk factors of any kind. When we translate this finding to the consumption of alcohol, it is shown that when drinking below a certain threshold namely "moderate drinking" the risk of developing cancer is equal or less compared to nondrinkers and would increase dramatically with the amount of alcohol ingested [42].

Previous studies have shown that the consumption of alcohol may be associated with a reduced risk of
NHL $[43,44]$. This finding may mirror the fact that the vast majority of $80 \%$ of our T-cell lymphoma patient are non-drinkers while only 6 out of the 30 patients were either former drinkers or are current drinkers. It was also presented that wine drinkers had an overall better survival compared to non-drinkers with NHL: the opposite was the case with the consumption of liquor. To transfer these findings to our cohort, a long-term follow-up is necessary as well as the assessment of the type of consumed alcohol to make precise differentiations. It is important to mention that the consumption of liquor goes along with a lower socio-economic status which could be on its own a risk factor for the development of malignancies. The opposite is valid for the consumption of wine. Additionally, it was shown that wine does not only have a positive influence on the survival of NHL patients but also prevents its relapse and the development of secondary cancers. This phenomenon may be scientifically supported by the theory that the polyphenolic constituents in grapes such as flavonoids and resveratrol, block the carcinogenesis by its anti-oxidative and anti-inflammatory properties. Contrary to these propositions other studies have shown that the consumption of alcohol is correlated with a poorer outcome of NHL patients in terms of survival and the increased risk of death. These findings confirm our hypothesis of a correlation between alcohol consumption and T-cell lymphoma development. This study also states that cigarette smoking is associated with a poorer overall survival in NHL [45]. This aspect would be of value to take into consideration in the follow up of our cohort; 25 out of 30 patients, $83.33 \%$ of our cohort have never smoked and thus reached statistical significance ( $p=0.00256)$.

This finding raises the hypothesis of smoking as a protective factor for T-cell lymphoma and should be taken into account to establish a correlation between smoking and T-cell lymphoma development when conducting a larger scale cohort in future research. In a future study with a larger cohort it would be also worthwhile to establish a certain threshold or cut-off value for alcohol consumption and the proportional increase in the risk to develop lymphomas. This could validate the assumption that a J-shaped risk curve is also applicable in the correlation between alcohol and T-cell lymphomas. Unfortunately, we cannot make a noteworthy statement regarding this hypothesis because just 6 out of $30(20 \%)$ patients were either drinkers or former drinkers with three consuming between 1-149 $\mathrm{g} /$ week and only one over $300 \mathrm{~g} /$ week of alcohol.

Our data demonstrate that the most common extranodal involvement of T-cell lymphoma patients is represented in decreasing order by bone marrow, the peritoneum, rhino-oropharynx and the liver-biliary system. Nodal involvement in mainly represented in decreasing order by the laterocervical, axillary, mediastinal and inguinal regions. These findings may be of value in further 
research and practical/clinical settings. Fever is the most common clinical feature and was present in 20 out of 30 $(66.67 \%)$ studied patients. Attention should also be directed to the area of living as rural/urban $(p=0.0605)$ came close to statistically significant; the same can be applied for educational status ( $p=0.0843)$.

Educational status is often linked with a higher or lower socioeconomic status. Our cohort had an equal distribution of educational status with $26.67 \%$ without education, $26.67 \%$ university, $23.33 \%$ gymnasium and $23.33 \%$ high school education. Due to this we cannot draw a conclusion if T-cell lymphoma development is associated with the socioeconomic status. The majority of studies are not conclusive if a low socioeconomic status is generally correlated with a higher risk of cancer development as the data vary depending on the type of cancer. One study states that a lower socioeconomic status is related with a late stage diagnosis of malignancies and consequently with poorer survival.

These factors deserve special attention when conducting a larger cohort in the future and may give an important insight regarding correlations to T-cell lymphoma development.

The major limitations of the study are in relation to the data collection, exact anamnesis and history of the patients is of crucial importance and should be documented precisely. Unfortunately, not enough attention was given to the alcohol exposure history of the patient which made it difficult to include patients in this study and which lead consequently to this relatively small cohort. To obtain precise statements with regard to volume frequency and history of alcohol consumption by the patients is another limiting factor as statements often are not reliable or precise enough to benefit from those. This is especially true in establishing a threshold in grams of alcohol consumed and the associated increasing risk for the development of malignancies. Also, the fact that T-cell lymphomas represent a minority of cancers, few cases are available in a geographically limited surrounding such as a single hospital or department. These limitations made it difficult to gather sufficient data to make statistically significant statements and to support our hypothesis. But the potential of the study was proven and gives a valuable cornerstone and starting point for further research in this area.

Unfortunately, this study did not have enough power to draw conclusions regarding the constructed hypothesis. The main reason is the limited number of patients in our cohort. Nevertheless, the study design has the potential to draw valid conclusions regarding correlations between risk factors and malignancy occurrence. A similar setup with a larger cohort is advisable for further research; a differentiation between the type of alcohol consumed, the volume, time period and drinking habits must be considered.

\section{Conclusion}

Although the understanding of NHL and T-cell lymphomas has improved over the years, further research on this pathology is necessary focusing on the many unanswered questions.

Large scale epidemiological studies need to be established to gain valuable insights into the development of T-cell lymphomas. Small studies such as ours may give the impetus for larger resource settings. The main conclusion from our cohort is that there is still no clear answer whether alcohol is a protective or risk factor.

Nevertheless we established the hypothesis that alcohol consumption might be a risk factor for developing AITL and should be tested in a larger cohort. $88.33 \%$ of our cohort never smoked cigarettes which raises the hypothesis of smoking as a protective factor for T-cell lymphoma. These findings should be put in focus when conducting further research.

\section{Acknowledgements}

Minodora Desmirean and Cedric Richlitzki contributed equally to the current paper and are both considered first author. Minodora Desmirean was financed from an internal grant of the School of Doctoral Studies - Iuliu Hatieganu University (PCD 2018-2021). Ciprian Tomuleasa was also supported by two national research grants of the Romanian Government: the first one awarded for Frontiers Research Projects 2018-2022 (grant number PN-III-P4-ID-PCCF-2016-112), awarded to the Babes Bolyai University in collaboration with the Ion Chiricuta Oncology Institute Cluj Napoca. Also a second one, awarded for Young Research Teams 2020-2022 (grant number PN-III-P1-1.1-TE-2019-0271) awarded to the Iuliu Hatieganu University of Medicine and Pharmacy Cluj Napoca. Ciprian Tomuleasa, Bobe Petrushev and Delia Dima were also financed by an international collaborative grant of the European Economic Space between Romania and Iceland 2020-2022 (grant number 19-COP-0031).

\section{References}

1. Shankland KR, Armitage JO, Hancock BW. Non-Hodgkin lymphoma. Lancet. 2012;380:848-857.

2. Luna-Abanto J, Ruiz LG, Laura-Martinez J, TairoCerron T. Cancer incidence and mortality trends in young adults in Metropolitan Lima young adults, 1990-2012. Ecancermedicalscience. 2020;14:1025.

3. Latifovic L, Freeman LEB, Spinelli JJ, Pahwa M, Kachuri L, Blair A, et al. Pesticide use and risk of Hodgkin lymphoma: results from the North American Pooled Project (NAPP). Cancer Causes Control. 2020;31:583-599.

4. Phan A, Veldman R, Lechowicz MJ. T-cell lymphoma Epidemiology: the Known and Unknown. Curr Hematol Malig Rep. 2016;11:492-503. 
5. Lim ST, Hee SW, Quek R, Lim LC, Yap SP, Loong EL, et al. Comparative analysis of extra-nodal NK/T-cell lymphoma and peripheral T-cell lymphoma: significant differences in clinical characteristics and prognosis. Eur J Haematol. 2008;80:55-60.

6. Reimer P, Hentrich M. [Peripheral T-cell lymphoma: diagnosis and treatment]. Dtsch Med Wochenschr. 2006;131:685-690 [German].

7. Marchi E, O'Connor OA. The rapidly changing landscape in mature T-cell lymphoma (MTCL) biology and management. CA Cancer J Clin. 2020;70:47-70.

8. Sas V, Pasca S, Jurj A, Pop L, Muramatsu H, Ono H, et al. MicroRNA-155-5p Plays a Critical Role in Transient Leukemia of Down Syndrome by Targeting Tumor Necrosis Factor Receptor Superfamily Members. Cell Physiol Biochem. 2020;54:994-1012.

9. Desmirean M, Rauch S, Jurj A, Pasca S, Iluta S, Teodorescu P, et al. B Cells versus T Cells in the Tumor Microenvironment of Malignant Lymphomas. Are the Lymphocytes Playing the Roles of Muhammad Ali versus George Foreman in Zaire 1974? J Clin Med. 2020;9:3412.

10. Grewal R, Irimie A, Naidoo N, Mohamed N, Petrushev B, Chetty $\mathrm{M}$, et al. Hodgkin's lymphoma and its association with EBV and HIV infection. Crit Rev Clin Lab Sci. 2018;55:102-114.

11. Gafencu GA, Selicean SE, Petrushev B, Cucuianu A, Dima D, Frinc I, et al. Clinicopathological analysis of a case series of peripheral T-cell lymphomas, not otherwise specified, of lymphoepithelioid variant (Lennert's lymphoma). A Central European single-center study. Hum Pathol. 2016;53:192194.

12. Chen Z, Wang M, Guan P, Zhao S, Zhang W, Gao L, et al. Comparison of Systemic EBV-positive T-Cell and NKCell Lymphoproliferative Diseases of Childhood Based on Classification Evolution: New Classification, Old Problems. Am J Surg Pathol. 2020;44:1061-1072

13. Chiu E, Samra B, Tam E, Baseri B, Lin B, Luhrs C, et al. Clinical Characteristics and Outcomes of Caribbean Patients With Adult T-Cell Lymphoma/Leukemia at Two Affiliated New York City Hospitals. JCO Glob Oncol. 2020;6:548-556.

14. Haverkos BM, Pan Z, Gru AA, Freud AG, Rabinovitch R, $\mathrm{Xu}$-Welliver $\mathrm{M}$, et al. Extranodal NK/T Cell Lymphoma, Nasal Type (ENKTL-NT): An Update on Epidemiology, Clinical Presentation, and Natural History in North American and European Cases. Curr Hematol Malig Rep. 2020;11:514-527.

15. Wudhikarn K, Bunworasate U, Julamanee J, Lekhakula A, Ekwattanakit S, Khuhapinant A, et al. Event free survival at 24 months is a strong surrogate prognostic endpoint of peripheral T cell lymphoma. Hematol Oncol. 2019;37:578585.

16. Hong H, Li Y, Lim ST, Liang C, Huang H, Yi P, et al. A proposal for a new staging system for extranodal natural killer T-cell lymphoma: a multicenter study from China and Asia Lymphoma Study Group. Leukemia. 2020;34:2243-2248.

17. Fox CP, Civallero M, Ko YH, Manni M, Skrypets T, Pileri S, et al. Survival outcomes of patients with extranodal naturalkiller T-cell lymphoma: a prospective cohort study from the international T-cell Project. Lancet Haematol. 2020;7:e284e294.

18. Lee WJ, Jung JM, Won CH, Chang SE, Choi JH, Chan Moon $\mathrm{K}$, et al. Cutaneous extranodal natural killer/T-cell lymphoma: a comparative clinicohistopathologic and survival outcome analysis of 45 cases according to the primary tumor site. J Am Acad Dermatol. 2014;70:1002-1009.

19. Nathan PE, Conrad M, Skinstad AH. History of the Concept of Addiction. Annu Rev Clin Psychol. 2016;12:29-51.

20. Collins SE. Associations Between Socioeconomic Factors and Alcohol Outcomes. Alcohol Res. 2016;38:83-94.

21. Huckle T, You RQ, Casswell S. Socio-economic status predicts drinking patterns but not alcohol-related consequences independently. Addiction. 2010;105:11921202.

22. Mäkelä P, Paljärvi T. Do consequences of a given pattern of drinking vary by socioeconomic status? A mortality and hospitalisation follow-up for alcohol-related causes of the Finnish Drinking Habits Surveys. J Epidemiol Community Health. 2008;62:728-733.

23. Sydén L, Sidorchuk A, Mäkelä P, Landberg J. The contribution of alcohol use and other behavioural, material and social factors to socio-economic differences in alcohol-related disorders in a Swedish cohort. Addiction. 2017;112:1920-1930.

24. Dawson DA, Room R. Towards agreement on ways to measure and report drinking patterns and alcohol-related problems in adult general population surveys: the Skarpö conference overview. J Subst Abuse. 2000;12:1-21.

25. Demers A, Garretsen H, Room R, Rossow I, Ugland T. Kettil Bruun Society for Social and Epidemiological Research on Alcohol. Addiction. 2004;99:161-164.

26. Maruyama K, Higuchi S. The Japanese society of alcoholrelated problems. Addiction. 2004;99:419-424.

27. Adamson SJ, Sellman JD, Frampton CM. Patient predictors of alcohol treatment outcome: a systematic review. J Subst Abuse Treat. 2009;36:75-86.

28. Peacock A, Leung J, Larney S, Colledge S, Hickman M, Rehm J, et al. Global statistics on alcohol, tobacco and illicit drug use: 2017 status report. Addiction. 2018;113:19051926.

29. GBD 2016 Alcohol and Drug Use Collaborators. The global burden of disease attributable to alcohol and drug use in 195 countries and territories, 1990-2016: a systematic analysis for the Global Burden of Disease Study 2016. Lancet Psychiatry. 2018;5:987-1012.

30. Cho YE, Mezey E, Hardwick JP, Salem N Jr, Clemens DL, Song BJ. Increased ethanol-inducible cytochrome $\mathrm{P} 450-2 \mathrm{E} 1$ and cytochrome P450 isoforms in exosomes of alcohol-exposed rodents and patients with alcoholism through oxidative and endoplasmic reticulum stress. Hepatol Commun. 2017;1:675-690.

31. Potter JJ, Mezey E. Acetaldehyde increases endogenous adiponectin and fibrogenesis in hepatic stellate cells but exogenous adiponectin inhibits fibrogenesis. Alcohol Clin Exp Res. 2007;31:2092-2100.

32. Oyama T, Isse T, Kagawa N, Kinaga T, Kim YD, Morita M, et al. Tissue-distribution of aldehyde dehydrogenase 2 and 
effects of the ALDH2 gene-disruption on the expression of enzymes involved in alcohol metabolism. Front Biosci. 2005;10:951-960.

33. Na HK, Lee JY. Molecular Basis of Alcohol-Related Gastric and Colon Cancer. Int J Mol Sci. 2017;18:1116.

34. Zakhari S. Overview: how is alcohol metabolized by the body? Alcohol Res Health. 2006;29:245-254.

35. Seitz HK, Becker P. Alcohol metabolism and cancer risk. Alcohol Res Health. 2007;30:38-41, 44-47.

36. Casswell S, Rehm J. Reduction in global alcohol-attributable harm unlikely after setback at WHO Executive Board. Lancet. 2020;395:1020-1021.

37. Jelski W, Szmitkowski M. Alcohol dehydrogenase (ADH) and aldehyde dehydrogenase (ALDH) in the cancer diseases. Clin Chim Acta. 2008;395:1-5.

38. Sharp CA, Bellis MA, Hughes K, Ford K, Di Lemma LCG. Public acceptability of public health policy to improve population health: A population-based survey. Health Expect. 2020;23:802-812.

39. Rehm J, Kailasapillai S, Larsen E, Rehm MX, Samokhvalov $\mathrm{AV}$, Shield KD, et al. A systematic review of the epidemiology of unrecorded alcohol consumption and the chemical composition of unrecorded alcohol. Addiction. 2014;109:880-893.

40. Rehm J, Crépault JF, Wettlaufer A, Manthey J, Shield K. What is the best indicator of the harmful use of alcohol? A narrative review. Drug Alcohol Rev. 2020;39:624-631.

41. Boffetta P, Hashibe M. Alcohol and cancer. Lancet Oncol. 2006;7:149-156.

42. Chajès V, Romieu I. Nutrition and breast cancer. Maturitas. 2014;77:7-11.

43. Han X, Zheng T, Foss FM, Ma S, Holford TR, Boyle P, et al. Alcohol consumption and non-Hodgkin lymphoma survival. J Cancer Surviv. 2010;4:101-109.

44. Geyer SM, Morton LM, Habermann TM, Allmer C, Davis $\mathrm{S}$, Cozen W, et al. Smoking, alcohol use, obesity, and overall survival from non-Hodgkin lymphoma: a population-based study. Cancer. 2010;116:2993-3000.

45. Battaglioli T, Gorini G, Costantini AS, Crosignani P, Miligi L, Nanni O, et al. Cigarette smoking and alcohol consumption as determinants of survival in non-Hodgkin's lymphoma: a population-based study. Ann Oncol. 2006;17:1283-1289. 